\title{
A prospective study of adverse drug reactions associated with chemotherapy in patients of carcinoma head and neck in Government Cancer Hospital Indore, India
}

\author{
Sameer Pandit ${ }^{1}$, Manish Verma ${ }^{2 *}$, Pooja Solanki Mishra ${ }^{1}$
}

${ }^{1}$ Department of Pharmacology, M.G.M. Medical College, Indore, Madhya Pradesh, India
${ }^{2}$ Department of Radiation Oncology, Government Cancer Hospital, Indore, Madhya Pradesh, India

Received: 24 February 2020

Revised: 06 May 2020

Accepted: 08 May 2020

*Correspondence:

Dr. Manish Verma,

Email: drmverma24@gmail.com

Copyright: (C) the author(s), publisher and licensee Medip Academy. This is an open-access article distributed under the terms of the Creative Commons Attribution Non-Commercial License, which permits unrestricted non-commercial use, distribution, and reproduction in any medium, provided the original work is properly cited.

\begin{abstract}
Background: Adverse drug reactions (ADRs) has become one of the major health issues due to wide use of medications worldwide. Chemotherapy is one of the treatment lines in which multiple drugs are commonly used for long term in cancer patients, are more prone to cause ADR.

Methods: Head and neck cancer patients admitted in government cancer hospital, Indore for chemotherapy were included in study for a period of 6 month from March to August 2019. Data from chemotherapy related ADR was obtained either from patient's case reports or interview of patients, recorded in suspected adverse drug reaction reporting form (version 1.3) of CDSCO and analyzed.

Results: During 6 months duration total 126 patients $(\mathrm{M}: \mathrm{F}=108: 18)$ were enrolled in the study, among which 251 ADRs were reported. Majority of ADRs occur in 45-60 years of age group followed by 30-45 years. Paclitaxel, cisplatin, 5-florouracil (5-FU) combinations (45.2\%) implicated highest number of ADRs followed by paclitaxel and carboplatin combination (38\%). Most common ADR was alopecia and constipation. ADR related mostly with GIT system followed by integumentary, haematological system while CNS was least affected.

Conclusions: In this study Ca tongue was most commonly seen head and neck cancer followed by Ca buccal mucosa. Age group 45-60 years were commonly affected. Paclitaxel, cisplatin, 5-FU combination was commonly used regimen and primary cause of ADR. Alopecia and constipation were noted to be most common ADR. Other ADRs reported were mild and easily manageable.
\end{abstract}

Keywords: Adverse drug reactions, Chemotherapy, Head and neck cancer

\section{INTRODUCTION}

Head and neck cancers include cancers of larynx, throat, lips, mouth, nose, and salivary glands. The major risk factor for head and neck cancers are usage of tobacco, heavy alcohol, and infection with human papilloma virus (HPV).

Chemotherapy is one of the approaches to be employed for the treatment of many tumors. ${ }^{1}$ The regimens are extremely complex and tolerance capacity of cancer patient is quite low that is why these are more susceptible population. $^{2}$

Pharmacovigilance is defined by the world health organization (WHO) as the science and activity related to the detection, assessment, understanding and prevention of adverse effects or any other drug related problem. ${ }^{3}$ Activities under pharmacovigilance programme of India (PvPI) include collection, reporting, and follow-up of 
adverse drug reactions (ADRs) occurring in patients. The PvPI collate the data received from various adverse drug reaction monitoring centres (AMCs) in the country and submit them on regular basis to global database maintained at Uppsala, Sweden.

Adverse drug reactions (ADRs) are a worldwide problem associated with the use of drugs for treatment of disease. According to World Health Organisation (WHO), ADR can be defined as a response to a drug, which is noxious and unintended, and which occurs at doses normally used in man for the prophylaxis, diagnosis, or therapy of disease, or for the modifications of physiological function. ${ }^{4}$ The number of studies conducted during the last decade has been demonstrated that drug induced morbidity and mortality associated with ADR is one of the major public health issue. Healthcare system of a country is imposed a huge financial burden because of ADR Drug induced complication are major concern because it takes up to $20 \%$ of health budget of some country. ${ }^{5,6}$ It is reported that elderly and hospitalized patients are more susceptible to ADRs than the adult population $(16.6 \%$ vs. $4.1 \%) .^{7}$ Recent studies indicate that ADRs are fourth to sixth leading cause of death worldwide. ${ }^{8}$ ADRs impact on patients includes the lowering of quality of life, increase in number of hospitalizations, increased economic burden on health management and increased rate of morbidity and mortality. Suspected ADRs are also categorized as serious and nonserious. Serious ADR is defined as any ADR which is fatal, life-threatening, permanently/significantly disabling, required initial hospitalization, or prolonged hospitalization, caused a congenital anomaly, required intervention to prevent permanent impairment or damage. ${ }^{9}$

Objective of this study is to assess and analyze the adverse drug reactions associated with chemotherapy in the patients of carcinoma head and neck.

\section{METHODS}

This was a prospective observational study conducted in the Department of Pharmacology, MGM Medical College, Indore. All the spontaneous adverse drug reaction reports due to cancer chemotherapeutic medications in head and neck cancer patients, which were submitted to the Department of Pharmacology, MGM medical College, Indore, under the pharmacovigilance programme of India in the past six months were included in the study.

ADR of head and neck cancer patients admitted for chemotherapy were recorded by postgraduate student of pharmacology department under guidance of senior consultant of cancer department. The ADR occur after chemotherapy were recorded either from patient's case sheet or by interviewing the patients and noted in suspected adverse drug reaction reporting form (version 1.3) provided by CDSCO website.
Data related with patients' demographic profile, ADR, drug regimen, types of cancer, and system involvement were collected by these ADR reporting forms and entered in master chart and calculated the frequency of ADR, drug regimen, types of cancer and demographic characteristics by simple percentage methods.

\section{Ethical approval}

This is an observational study in which data of ADR was collected routinely in our department under the pharmacovigilance programme of India.

\section{RESULTS}

Total 126 patients were enrolled in the study in the duration of 6 months in which Ca tongue $(26.1 \%)$ and $\mathrm{Ca}$ buccal mucosa $(23.8 \%)$ were very frequent while others were less. In the present study the most common age group affected with head and neck cancer was 45 to 60 years followed by age group 60 above and ADR were also reported in these group of patients and male patients $(85.7 \%)$ were mostly affected than female patients (14.2\%) (Table 1).

Table 1: Age and sex wise distribution of patients.

\begin{tabular}{|llll|}
\hline Age in years & Male $(\mathbf{N})$ & Female $(\mathbf{N})$ & Total \\
\hline $\mathbf{1 5 - 3 0}$ & 6 & 0 & 6 \\
\hline $\mathbf{3 0 - 4 5}$ & 30 & 6 & 36 \\
\hline $\mathbf{4 5 - 6 0}$ & 48 & 9 & 57 \\
\hline 60 above & 24 & 3 & 27 \\
\hline Total & 108 & 18 & 126 \\
\hline
\end{tabular}

Table 2: Distribution of patients on the basis of type of head and neck cancer.

\begin{tabular}{|lll|}
\hline Types & $\begin{array}{l}\text { Number of } \\
\text { patients }\end{array}$ & Percentage \\
\hline Ca tongue & 33 & 26.1 \\
\hline Ca buccal mucosa & 30 & 23.8 \\
\hline Ca larynx & 18 & 14.2 \\
\hline Ca alveolus & 15 & 11.9 \\
\hline Ca epiglottis & 9 & 7.1 \\
\hline Ca pharynx & 9 & 7.1 \\
\hline Ca soft palate & 3 & 2.3 \\
\hline Ca retromolar trigone & 3 & 2.3 \\
\hline Ca pyriform fossa & 3 & 2.3 \\
\hline Ca tonsil & 3 & 2.3 \\
\hline
\end{tabular}

The cancer affected the various site in head and neck region and the patients mostly affected with $\mathrm{Ca}$ tongue $(26.1 \%)$ and $\mathrm{Ca}$ buccal mucosa $(23.8 \%)$ followed by $\mathrm{Ca}$ larynx (14.2\%), Ca alveolus (11.9\%), Ca pharynx (7.1\%), $\mathrm{Ca}$ epiglottis $(7.1 \%)$ as shown in Table 2

It was observed that most patients were taking multidrug treatment. Paclitaxel with cisplatin and 5-florouracil (5- 
FU) (45.2\%) based regimen was mostly prescribed followed by paclitaxel with carboplatin (38\%). In majority of patients multiple ADRs were reported.

Table 3: Commonly used drug regimen in head and neck cancer patients.

\begin{tabular}{|lll|}
\hline Drug regimen & $\begin{array}{l}\text { Number } \\
\text { of patients }\end{array}$ & Percentage \\
\hline $\begin{array}{l}\text { Paclitaxel, cisplatin and } \\
\text { 5-FU }\end{array}$ & 57 & 45.2 \\
\hline $\begin{array}{l}\text { Paclitaxel and } \\
\text { carboplatin }\end{array}$ & 48 & 38 \\
\hline $\begin{array}{l}\text { Docetaxel, cisplatin and } \\
\text { fluorouracil }\end{array}$ & 12 & 9.5 \\
\hline Cisplatin and 5-FU & 3 & 2.3 \\
\hline Paclitaxel & 6 & 4.7 \\
\hline
\end{tabular}

Table 4: ADR associated with chemotherapy in head and neck cancer patients.

\begin{tabular}{|lll|}
\hline ADR & $\begin{array}{l}\text { Number } \\
\text { of patients }\end{array}$ & Percentage \\
\hline Alopecia & 48 & 38 \\
\hline Constipation & 36 & 28.5 \\
\hline Vomiting & 33 & 26.1 \\
\hline Anorexia & 30 & 23.8 \\
\hline Mucositis & 24 & 19 \\
\hline Dizziness & 24 & 19 \\
\hline Diarrhoea & 18 & 14.2 \\
\hline Anemia & 14 & 11.1 \\
\hline Neutropenia & 13 & 10.3 \\
\hline Pigmentation of skin & 6 & 4.7 \\
\hline Thrombocytopenia & 5 & 3.9 \\
\hline
\end{tabular}

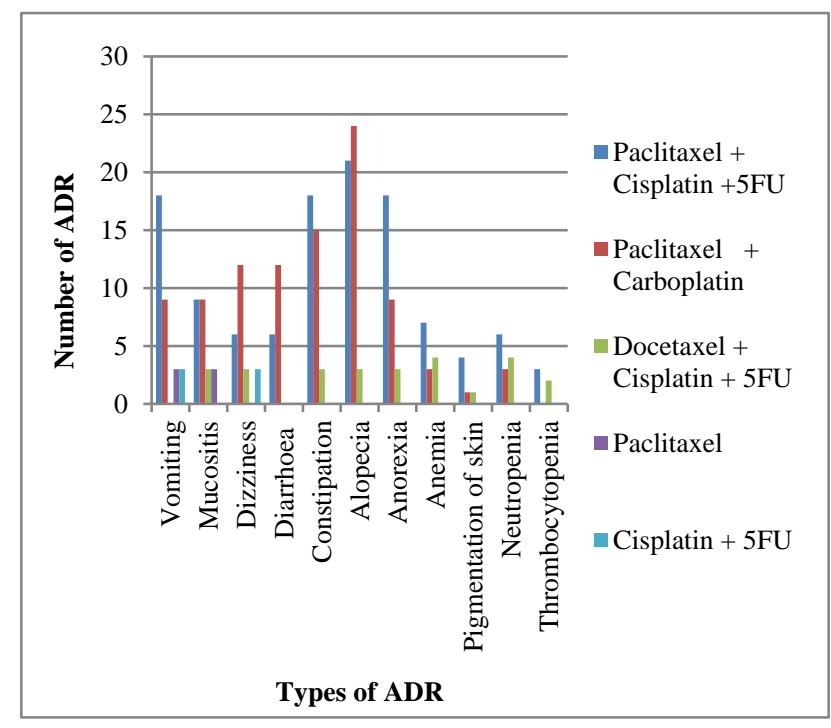

Figure 1: ADR associated with different drug combination.

Most of the ADR were associated with paclitaxel with cisplatin and 5-FU regimens $(46.2 \%)$ followed by paclitaxel and carboplatin (38.6\%) than docetaxel with cisplatin and 5-FU (10.3\%), cisplatin with 5-FU (2.3\%) and then paclitaxel alone (2.3\%) (Figure 1).

The incidence of ADRs associated with chemotherapy of head and neck cancer in the patients were as follows. Alopecia $(38 \%)$, constipation $(28.5 \%)$, vomiting $(26.1 \%)$, anorexia $(23.8 \%)$, mucositis $(19 \%)$, dizziness $(19 \%)$, diarrhoea $(14.2 \%)$ occurred in more frequency followed by anemia (11.1\%), neutropenia (10.3\%), skin pigmentation $(4.7 \%)$ and thrombocytopenia (3.9\%).

Thus, it is evident that GIT $(30.1 \%)$ was the most common system affected in ADR due to chemotherapy and integumentary system was significantly affected $(27.7 \%)$ as well. Involvement of haematological system was found to be $25.3 \%$ which is also notable. A considerable percentage of ADRs (11.1\%) was also observed in renal system. Least affected was the CNS (9.5\%) (Figure 2).

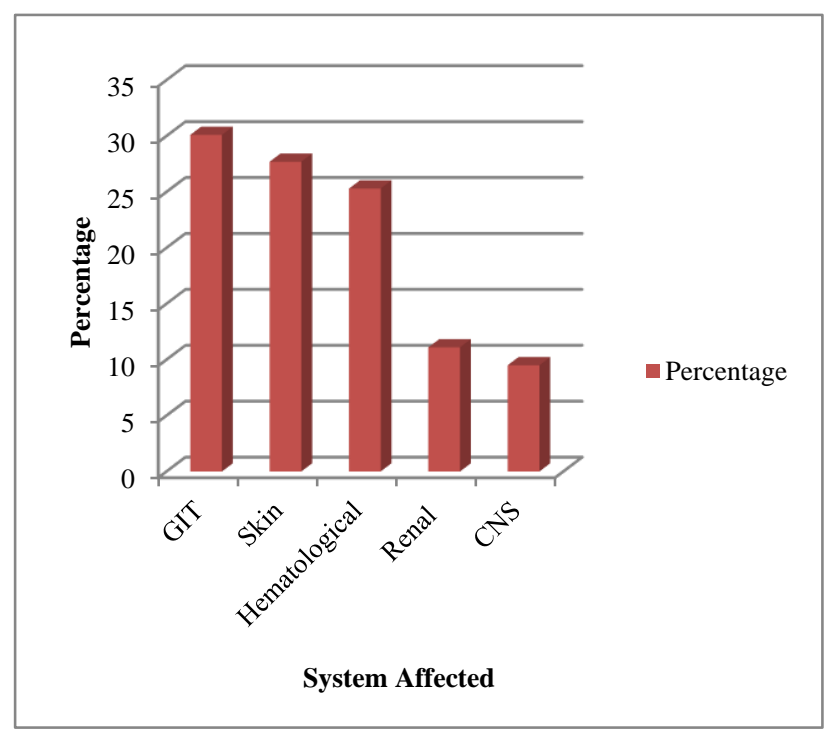

Figure 2: System affected due to ADR.

\section{DISCUSSION}

ADR associated with cancer chemotherapy gives an extra burden either through increased mortality risk or increased cost of therapy and it also affect the quality of life of patients. In our country only $1 \%$ of global data of ADR is reported and the reason can be low doctor to patient ratio and doctor or other health professionals are unable to report the ADR or unawareness of importance of reporting ADR.

All the patients collectively showed a total of 251 chemotherapy induced ADRs. The majority of ADR were occurring in 45-60 years of age group with male preponderance suggested that male individuals were more prone to exposed for risk factor such as tobacco chewing, smoking etc., these types of habits were least found in females (Table 1). 
The cancer affected the various site in head and neck region and the patients mostly affected with $\mathrm{Ca}$ tongue (26.1\%) and Ca buccal mucosa $(23.8 \%)$ followed by $\mathrm{Ca}$ larynx (14.2\%), Ca alveolus (11.9\%), Ca pharynx (7.1\%), Ca epiglottis $(7.1 \%)$ which might be due to that smoking and chewing tobacco in regular basis and this was the most common risk factor for $\mathrm{Ca}$ tongue and $\mathrm{Ca}$ buccal mucosa.

The most common regimen or drug used in head and neck cancer patients was paclitaxel cisplatin, 5-FU combination in 57 patients $(45.2 \%)$ followed by paclitaxel and carboplatin in 48 patients (38\%) while other regimens were less commonly used. The possible reason might be that these are more efficacious in patients and are used according to the recent guidelines.

Alopecia, constipation, vomiting, anorexia, mucositis, dizziness and diarrhoea are most common ADRs occur during chemotherapy because these drugs affect the related system by damaging the healthy cells, alter the intestinal motility and having emetogenic potential might be responsible for these ADR.

The drugs or combination of drugs are associated with ADR specifically. Figure 1, shows that vomiting, anorexia, constipation were more common with paclitaxel, cisplatin, 5-FU combination which were consistent with previous study done by Surendiran et al, while diarrhoea, dizziness, alopecia occur more with paclitaxel and carboplatin combination. ${ }^{10}$ However blood related adverse effect such as anemia, neutropenia, thrombocytopenia were more occur in paclitaxel, cisplatin, 5-FU combination while mucositis were equally found in both type of combinations and because these combinations were mostly used, hence associated with more number of ADRs, and other combinations were least used and least associated with ADRs.

The highest frequency of ADR was related with GIT system and lowest were related with CNS might be suggest that most of the drugs were GI intolerable so prefer to use drugs routinely with chemotherapeutic drugs which will counteract GI related adverse effects. We observed that in some patients during routine investigation creatinine value rises from normal limit or previous value imply that chemotherapeutic drugs affect the renal system.

Most of the ADRs were not preventable because of mechanism associated with ADRs were poorly understood. However, most of the ADRs were mild in nature and subside within a week and can be effectively controlled by pre medication so there is responsibility of a treating physician to counsel the patients adequately about adverse drug reaction prior to therapy. The results of this study show that ADRs were common with chemotherapeutic drugs and so there is need to improve pharmacovigilance awareness among physician and straighten pharmacovigilance system of India.

\section{CONCLUSION}

In the study it was seen that head and neck cancers, $\mathrm{Ca}$ tongue was most common followed by $\mathrm{Ca}$ buccal mucosa. Patients between 45-60 years of age were more commonly affected. Paclitaxel, cisplatin, 5-FU combination was the most commonly used regimen and hence was the primary cause of ADR. Alopecia and constipation were noted to be most common ADR. Other ADRs reported were mild and easily manageable. Early detection of chemotherapy-related ADRs through this study helped to improve outcome by better risk management plan, taking interventions on time and cautious use of agents with similar toxicity.

\section{ACKNOWLEDGEMENTS}

The authors would like to thank Dr. Ramesh Arya, Professor and HOD, MD Radiation Oncologist, Government Cancer Hospital, Indore.

\section{Funding: No funding sources}

Conflict of interest: None declared

Ethical approval: The study was approved by the Institutional Ethics Committee

\section{REFERENCES}

1. Chabner BA, Amrein PC, Druker BJ. Bruntan LL, Lazo JS, Parker KL. Goodman and Gilman's The Pharmacological Basis of Therapeutics. 11th ed. USA: MaGraw-Hill Companies, Inc; 2006. Antineoplastic agents. 2006;37(1):42-6.

2. Muller T. Typical medication errors in oncology: Analysis and prevention strategies. Onkologie. 2003;26:539-44.

3. WHO Policy Perspectives on Medicines. Geneva: WHO; 2004. Geneva: World Health Organization. Looking at the Pharmacovigilance: ensuring the safe use of medicines. Available at: http://www. whqlibdoc.who.int/hq/2004/WHO_EDM_2004.8.pdf. Accessed on 15 December 2009.

4. Glossary of Terms Used in Pharmacovigilance; January. 2013. Available at: http://www.whoumc. org/DynPage. aspx ?id=97224\&mn1=7347\&mn2=725 $2 \& \mathrm{mn} 3=7257$. Accessed on 30 July 2013.

5. De A. Monitoring of suspected adverse drug reactions in oncology unit of an urban multispeciality teaching hospital. Int J Res Pharm Biomed Sci. 2010;1:1-32.

6. Rottenkolber D, Schmiedl S, Rottenkolber M, Farker K, Salje K, Mueller S, et al. Adverse drug reactions in Germany: Direct costs of internal medicine hospitalizations. Pharmacoepidemiol Drug Saf. 2011;20:626-34.

7. Jose J, Rao PG. Pattern of adverse drug reactions notified by spontaneous reporting in an Indian tertiary care teaching hospital. Pharmacol Res. 2006;54:226-33. 
8. Brown SD, Landry FJ. Recognizing, reporting, and reducing adverse drug reactions. South Med J. 2001;94:370-3.

9. Safety of Medicines. Available at: http://www.whqlibdoc.who.int/hq/2002/.WHO_EDM _QSM_2002.2.pdf. Accessed on $2^{\text {nd }}$ January 2015.

10. Surendiren A, Balamurugan N, Gunaseelan K, Akhtar S, Reddy KS, Adithan C. Adverse drug reaction profile of cisplatin-based chemotherapy regimen in a tertiary care hospital in India: an evaluative study. Indian J Pharmacol. 2010;42(1):403.

Cite this article as: Pandit S, Verma M, Mishra PS. A prospective study of adverse drug reactions associated with chemotherapy in patients of carcinoma head and neck in Government Cancer Hospital Indore, India. Int J Basic Clin Pharmacol 2020;9:897-901. 